\title{
Uma nova espécie de Amblyscartidia Young, 1977 (Homoptera, Cicadellidae, Cicadellinae) ${ }^{1}$
}

\author{
R. R. Cavichioli ${ }^{2,3}$ \\ A. M. Sakakibara ${ }^{3}$
}

\begin{abstract}
Amblyscartidia trifasciata $s p$. $n$. is described from Silva Jardim - RJ, Brazil. (Homoptera, Cicadellidae, Cicadellinae).

O gênero Amblyscartidia está constituído por dez espécies, nove das quais são representantadas no Brasil (YOUNG, 1977). Este gênero caracteriza-se por apresentar o edeago alargado, paráfise simétrica e meron oculto quando as tégminas em repouso.
\end{abstract}

\section{Amblyscartidia trifasciata sp. $\mathbf{n}$.}

(Figs. 1 - 9)

Medidas (em mm) Macho/Fêmea: comprimento da cabeça: 0,64/0,64; distância transocular: $2,40 / 2,48$; distância interocular: $1,48 / 1,56$; distância ocelocular: $0,32 / 0,36$; distância interocelar: $0,72 / 0,72$; comprimento do pronoto: 1,20/1,20; distância entre os úmeros: $2,04 / 2,24$; comprimento das tégminas: 7,08/7,52; largura máxima das tégminas: $2,00 / 2,08$; comprimento total: 8,72 / 9,20 .

Localidade - tipo: Holótipo. BRASIL. Rio de Janeiro. Silva Jardim, III-74, F.M. Oliveira leg. Parátipos: BRASIL. Rio de Janeiro. Silva Jardim, III-74, 1 \%, F.M. Oliveira leg. Ibidem, VIII-74, 1 ㅇ, F.M. Oliveira leg. (MZUP).

Diagnose: Esta espécie é semelhante a $A$. juliacoides Young porém, difere por ter a paráfise com o talo maior do que os ramos e estes últimos serem alargados apicalmente, e o conetivo fortemente carenado dorsomedianamente. 0 edeago segue o padrão do gênero.

Holótipo macho. Cabeça, em vista dorsal, com comprimento 3/7 a 4/9 da distância interocular e $1 / 4$ a $2 / 7$ da distância transocular; margem anterior levemente arredondada. Ocelos situados atrás da linha imaginária que tangencia os bordos anteriores dos olhos, separados entre si por uma distância duas vezes a distância ocelocular; superficie lisa, com três fóveas: duas laterais, a cada lado

1 Contribuição n! 630, do Departamento de Zoologia da Universidade Federal do Paraná.

2 Entomólogo do Centro de Identificação de Insetos Fitófagos.

3 Departamento de Zoologia - UFPR. Caixa Postal 19030, 81504 Curitiba - Paraná. Bolsistas do CNPq. 


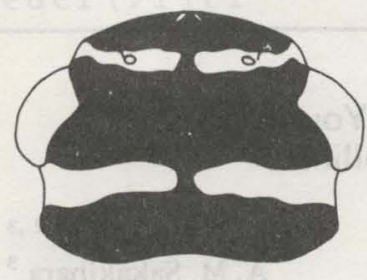

1

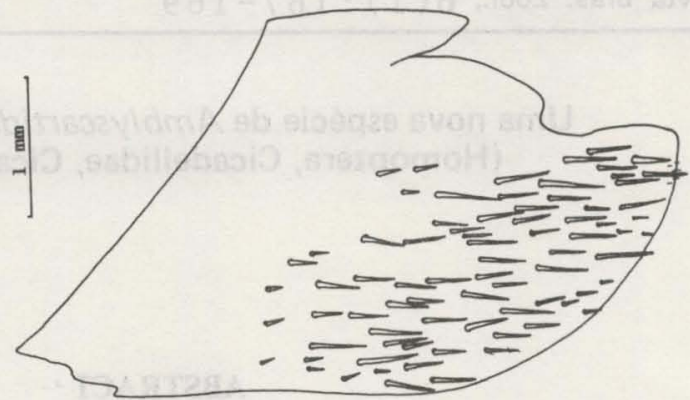

2

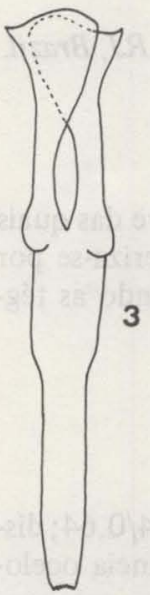

3
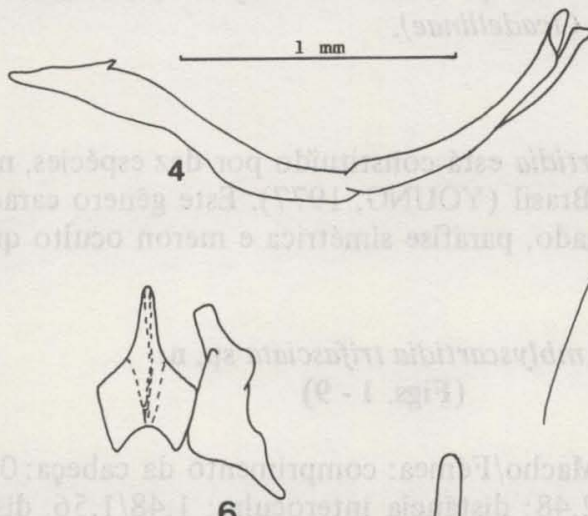

6

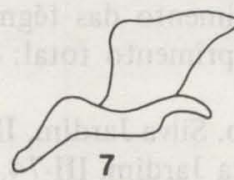

8
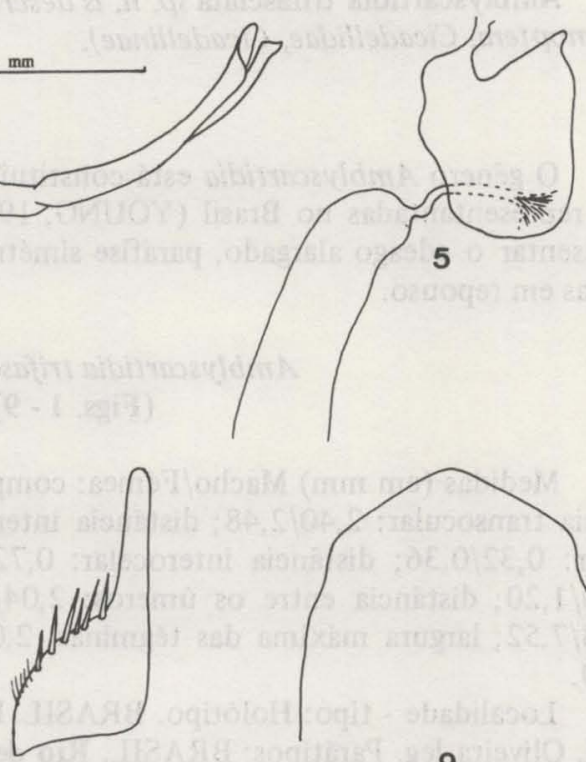

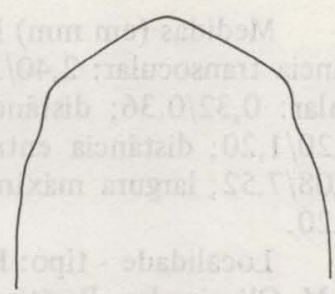

9

FIGS. 1 - 9 -Amblyscartidia trifasciata sp. n. (Holótipo); 1 - Cabeça em vista dorsal; 2 Pigóforo em vista lateral; 3 - Paráfise em vista dorsal; 4 - Paráfise em vista lateral; 5 - Edeado em vista lateral; 6 - Parâmero e conetivo em vista dorsal; 7 - Parâmero e conetivo em vista lateral; 8 - Placa subgenital em vista ventral; 9 - Placa subgenital da fêmea em vista ventral (Parátipo).

dos ocelos e uma entre os mesmos; suturas laterais do clippeo estendendo-se sobre a coroa e atingindo os ocelos; lóbulos suprantenais protuberantes, em vista lateral, com os bordos arredondados e oblíquos; clípeo com comprimento mediano aproximadamente $3 / 4$ da sua largura máxima, pouco achatado medianamente, com impressões musculares obscuras; sutura transclipeal nitida e completa; anteclípeo mais longo do que largo, de perfil com sua porção inferior levemente an- 
gulada com o clípeo. Rostro atingindo as mesocoxas. Pronoto mais estreito do que a cabeça; comprimento mediano $4 / 7$ a $3 / 5$ da largura entre os úmeros; margens laterais paralelas e a posterior mais ou menos reta; carena notopleural inteira; superfĩcie lisa. Escutelo mais largo do que longo e sem esculturações. Tégminas três vezes e meia mais longas do que largas; apêndice curto; margem apical arredondada; veias obscuras e não elevadas; três células anteapicais fechadas e quatro células apicais; fórmula setal dos fêmures posteriores 2.1.1. Pigóforo, em vista lateral, mais longo do que largo, margem dorsoapical angulada, macrocerdas distribuĩdas desde o terço basal até o ápice, processos ausentes. Placa subgenital triangular, bipartida, tão larga quanto longa, abruptamente afilada do meio para o ápice, com uma fileira de macrocerdas. Parâmeros robustos, mais curtos que o conetivo, com ápice truncado. Conetivo em Y, com uma forte carena mediana longitudinal. Edeago quase duas vezes mais largo do que longo, margem inferior curva e a dorsoapical pontiaguda, gonóporo na parte ventroapical; paráfise simétrica, talo mais longo do que os ramos, estes últimos com ápice alargado, denteado e sobrepondo-se um ao outro.

Fêmea: Idêntica ao macho, sendo um pouco maior. Pigóforo de forma triangular, alongado, com macrocerdas distribuídas no seu terço posterior. Placa subgenital, quase tão longa quanto larga, carenada medianamente, margem posterior levemente angulada.

Coloração: Cabeça preta com uma faixa branca, transversa, estreita, estendendo-se de uma orla a outra, passando pelos ocelos. Clippeo com uma faixa longitudinal medianamente e duas pequenas formando um V no ápice. Pronoto preto com um pequeno ponto branco mediano junto à margem anterior; uma faixa transversa mediana estendendo-se às pleuras. Escutelo com duas manchas brancas: uma junto ao pronoto e outra no ápice. Tégminas pretas, brilhantes, com quatro faixas brancas, sendo três longitudinais: a maior, junto à veia Média estendendo-se desde a base até o terço apical; a outra, pouco menor, na região do clavo, quase paralela à anterior; a terceira, bem menor, junto ao clavo e quase continua com a segunda e a quarta transversa, junto às células apicais. Tórax e pernas marron-claros.

\section{REFERENCIAS}

YOUNG, D.A. 1977. Taxonomic Study of the Cicadellinae (Homoptera: Cicadellidae).

Part 2. New World Cicadellini and the genus Cicadella. Technical Bull., 239:1-1109. 